\title{
Aerosol Optical and Micro-Physical Characteristic Derived from AERONET in Kenya*
}

\author{
Misiani Zachary ${ }^{1,2}$, Shengjie Niư ${ }^{3}$, Jingjing Lü ${ }^{3}$ \\ ${ }^{1}$ School of Atmospheric Sciences, Nanjing University of Information Science and Technology, Nanjing, China \\ ${ }^{2}$ Kenya Meteorological Department, Ministry of Environment \& Natural Resources, Nairobi, Kenya \\ ${ }^{3}$ Key Laboratory of Meteorological Disaster of Ministry of Education, School of Atmospheric Physics, \\ Nanjing University of Information Science and Technology, Nanjing, China \\ Email: zacharymisiani@gmail.com
}

How to cite this paper: Zachary, M., Niu, S.J. and Lü, J.J. (2018) Aerosol Optical and Micro-Physical Characteristic Derived from AERONET in Kenya. Open Access Library Journal, 5: e4551.

https://doi.org/10.4236/oalib.1104551

Received: March 28, 2018

Accepted: April 24, 2018

Published: April 27, 2018

Copyright $\odot 2018$ by authors and Open Access Library Inc.

This work is licensed under the Creative Commons Attribution International License (CC BY 4.0).

http://creativecommons.org/licenses/by/4.0/

\begin{abstract}
The identification and classicization of both natural and anthropogenic atmospheric aerosols originating from different region is becoming very useful when dealing with effect of air quality. Different areas may encounter the problem of dust storm events which is harmfully to the environment and human health. This thesis works focused mainly on the evaluation of level 1.5 data from Sunphotometer remote sensing to understand the micro-physical aerosol optical features which includes the time series analysis, aerosol properties, absorption and its classification for the hot dry season (December-February), intermediate to heavier rainy season (March-May), the cooler dry season (June-August) and short rains season (September-November). The annual mean aerosol optical depth (AOD) and extinction Ångström exponent (EAE) were $0.27 \pm 0.17$ and $1.01 \pm 0.33$ respectively. It was observed that mixed aerosols type was more dominance followed by the biomass burning (BB) and urban-industrial (UI) aerosols. During hot dry season, the mean values of $\mathrm{AOD}$ were observed to be higher than those recorded during rainy period. The volume size distribution graphs clearly indicate a bimodal whereby fine mode was more prevailing in hot dry season whereas coarse mode dominated in rainy season.
\end{abstract}

\section{Subject Areas}

Atmospheric Sciences

\footnotetext{
${ }^{*}$ A huge diversity of aerosol types, size, composition \& its heterogeneous distribution in temporal and spatial embody a great challenge in identifying the dominant aerosol type. Ground-based sensors such as AERONET stations are used to infer microphysical properties of aerosols based on measurements of their optical properties.
} 


\section{Keywords}

Aerosol Optical Depth (AOD), Ångström Exponent (AE), Extinction Ångström Exponent (EAE), Single Scattering Albedo (SSA)

\section{Introduction}

Atmospheric aerosol is the suspension of liquid and solid particles with varying diameter mostly range from a few nanometers to tens of micrometers in the atmosphere and according to their size, aerosols may be classified into three categories viz. a) Nucleation mode particles (0.001 - $0.1 \mu \mathrm{m}$ radius), b) Accumulation mode particles (0.1 $-1.0 \mu \mathrm{m}$ radius) and c) Coarse mode particles (greater than $1.0 \mu \mathrm{m}$ radius). Atmospheric aerosol particles play important role in solar radiation budget, climate change, hydrology process, air quality and visibility through the effect of scattering and absorption of incoming solar energy from the sun [1]. One of the most commonly characterized aerosol properties is the Aerosol Optical Depth (abbreviated by AOD), defined as the integration of the extinction coefficient over a vertical column of unit cross section [2].

Much progress has been made during recent years in ground based remote sensing of aerosol optical properties across the world. The comprehensive Sunphotometer ground-based remote sensing networks such as the Aerosol Robotic Network (AERONET; e.g., [3]) have been widely established and produce a continuous datasets in various parts of the globe. Therefore, there is availability of continuing AOD time series with very high temporal resolutions from some of these selected stations through the global network of ground-based radiometers [4].

This study firstly examined the yearly and seasonal variations of the optical and micro physical properties of aerosols for ICIPE Mbita using AERONET data which included the Aerosol Optical Depth (AOD), Extinction Ångström Exponent (EAE), Single Scattering Albedo (SSA), Asymmetric Parameter (ASYM), Total amount of Precipitable Water (TPW) and aerosol volume size distributions. Secondly, major aerosol types were classified by using the Extinction Ångström Exponent (EAE) and Absorption Ångström Exponent (AAE). Lastly, the source and sinking points of aerosol particles were identified within the area of interest.

\section{Method, Site and Area of Study}

\subsection{Method}

Daily averages of AOD, EAE, SSA, ASYM, AAE, and the TPW and aerosol volume size distribution were calculated firstly based on the number of days with data, number of instantaneous data and then the monthly mean were obtained by calculating the average of the total number of days of a given month independently from the year. Finally, the monthly and seasonal means were analyzed 
to characterize the column-integrated aerosol properties Figure 1. The relationships of AAE vs. EAE were applied to infer the dominant aerosol types. AAE were calculated by using absorption AOD at 440, 675, and $870 \mathrm{~nm}$ versus wavelength at the logarithmic scale whereas EAE were also calculated from a linear regression of the same three mentioned wavelengths. The combination spectral difference between EAE (440 - 675) nm and EAE (675 - 870) nm were used as a graphic method for tracking mixtures of pollution containing dust based on AODs at a few wavelengths which was a good indicator to fine mode effective radius [5]. The seasonal aerosol size distributions binned by AOD was used to determine the variation of fine and coarse aerosols with increasing AOD. A straightforward graphical framework spaced on $\delta \alpha$ vs. EAE were employed to track mixtures of pollution aerosol with dust, to distinguish aerosol growth from cloud contamination and to examine aerosol humidification and finally a 120 hour back-trajectory calculation using the NOAA HYSPILT model was also used [6] [7].

\subsection{Site Description}

ICIPE Mbita station represents the most active aerosols monitoring station in Kenya with long-term data spanning from $24^{\text {th }}$ December 2006 to till date is located near the Southwestern border of Kenya and Uganda along the shores of Lake Victoria at the latitudes and longitudes of $0.42^{\circ} \mathrm{S}, 34.20^{\circ} \mathrm{E}$ respectively and $1125 \mathrm{~m}$ above sea level. Next to this station is also one of the third big city in Kenya, Kisumu City with a population of 409,928 [8]. Mbita is not only under the influence of lake-terrestrial air mass exchange [9], but also are affected by dust aerosols caused by the transport highways and biomass burning from the nearby rural areas.

\subsection{Area of Study (Figure 2)}

Data

The data for the above mentioned station was obtained from the Air Recourses Laboratory HYSPLIT MODEL http://www.ready.noaa.gov/index.php and AERONET dataset (https://aeronet.gsfc.nasa.gov/new_web/units.html) and level 1.5 all points' format data were used in this study. The level 1.5 data derived from the version 2 direct sun algorithm were used to analyze the AOD, EAE and TPW. The level 1.5 SSA, ASYM, and aerosol volume size distributions were derived from the version 2 inversion algorithm [10].

Table 1 and Table 2 are the statistics of sun direct and inversion data for the AERONET ground station which shows the distribution of the data counts over different months and years. From Table 1, it shows some months with higher recoded days with data, for example in December 2016, the days with data were $27 / 31$ whereas some days were with no recorded data. Because of daily changes of the local weather, the presence and the passage of clouds frequently interrupts clear-sky data leading to fewer days with recoded data. There is a direct relationship between the days with observed data and days with instantaneous 


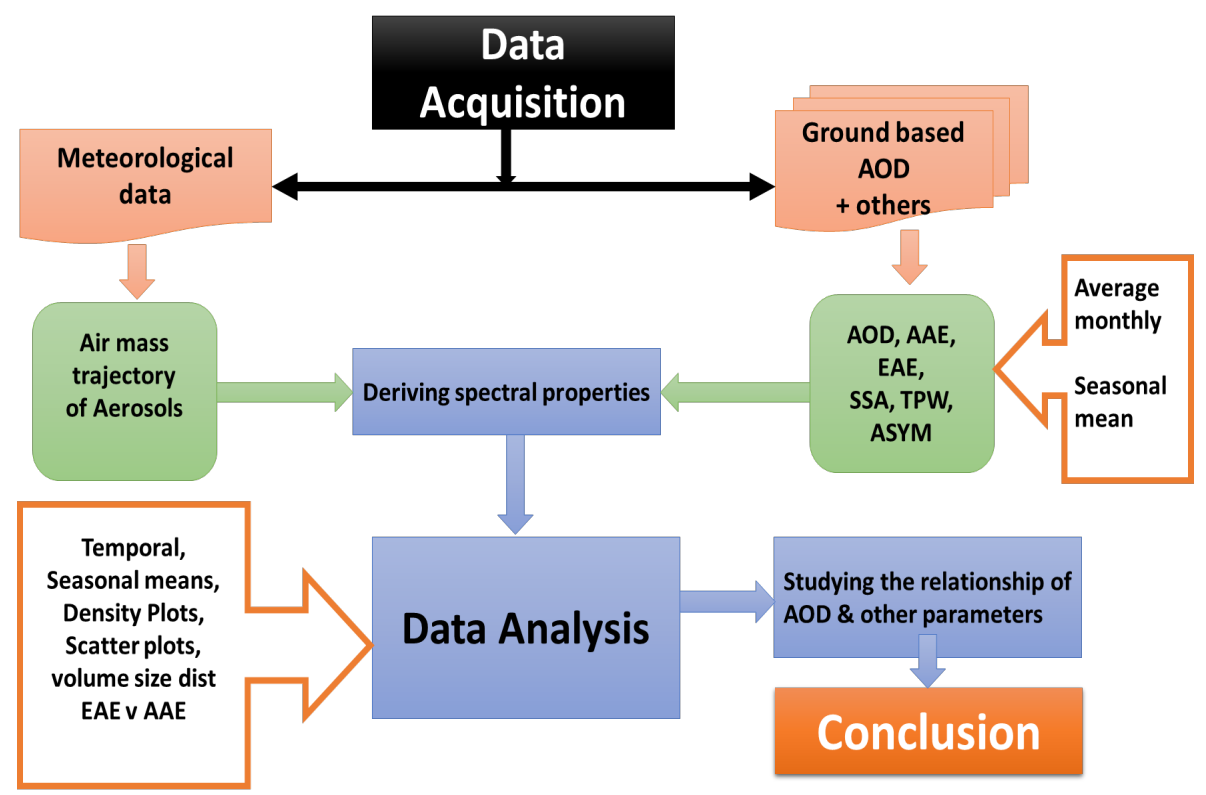

Figure 1. This flow chart diagrams the steps of this thesis methodology from the data acquisition to the conclusion.

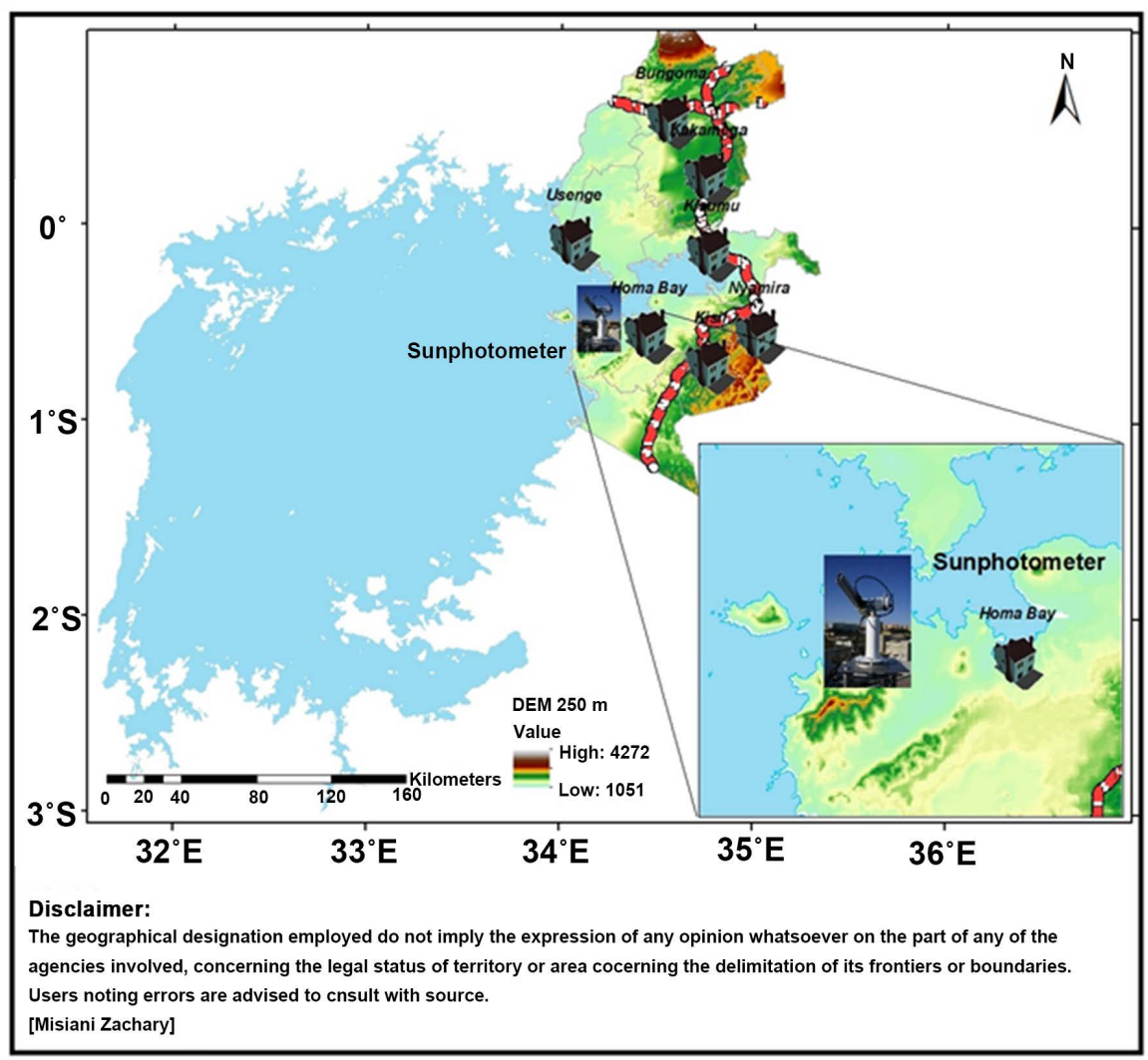

Figure 2. Geographical locations of the ICIPE Mbita AERONET site situated in Kenya drowned with ground based Sunphotometer $\left(0.42^{\circ} \mathrm{S}, 34.20^{\circ} \mathrm{E}\right)$, the houses represent the major towns within the area of study, blues color represent Lake Victoria while red with white line represent major roads. This map was plot by Misiani Zachary on $12^{\text {th }}$ Feb 2018. 
Table 1. ICIPE Mbita showing number of days with observed data.

\begin{tabular}{ccccccccccccc}
\hline \multicolumn{10}{c}{ Days with observed data ICIPE Mbita } \\
\hline Month & 2006 & 2007 & 2008 & 2009 & 2010 & 2011 & 2012 & 2013 & 2014 & 2015 & 2016 & TOTAL \\
\hline Jan & 0 & 21 & 1 & 0 & 2 & 22 & 0 & 12 & 4 & 0 & 7 & 69 \\
Feb & 0 & 21 & 19 & 0 & 2 & 20 & 0 & 12 & 5 & 0 & - & 79 \\
Mar & 0 & 23 & 26 & 0 & 12 & 22 & 18 & 0 & 17 & 0 & - & 118 \\
Apr & 0 & 10 & 3 & 0 & 7 & 23 & 4 & 0 & 0 & 5 & - & 52 \\
May & 0 & 20 & 7 & 0 & 3 & 18 & 0 & 16 & 0 & 16 & - & 80 \\
Jun & 0 & 15 & 13 & 0 & 15 & 9 & 10 & 8 & 14 & 20 & - & 104 \\
Jul & 0 & 23 & 19 & 0 & 19 & 18 & 9 & 24 & 19 & 23 & - & 154 \\
Aug & 0 & 23 & 0 & 0 & 16 & 14 & 10 & 12 & 15 & 13 & - & 103 \\
Sep & 0 & 18 & 0 & 0 & 9 & 17 & 0 & 0 & 6 & 23 & - & 73 \\
Oct & 0 & 20 & 0 & 8 & 16 & 10 & 24 & 19 & 0 & 14 & - & 111 \\
Nov & 0 & 15 & 0 & 5 & 14 & 8 & 11 & 12 & 0 & 10 & - & 75 \\
Dec & 27 & 2 & 0 & 7 & 21 & 8 & 7 & 11 & 0 & 7 & - & 90 \\
Total & 27 & 211 & 88 & 20 & 136 & 189 & 93 & 126 & 80 & 131 & 7 & 1108 \\
\hline & & & & & & & & & & & \\
\hline
\end{tabular}

Table 2. ICIPE Mbita showing number of instantaneous days with observed data.

\begin{tabular}{ccccccccccccc}
\hline \multicolumn{10}{c}{ Days with instantaneous data ICIPE Mbita } \\
\hline Month & 2006 & 2007 & 2008 & 2009 & 2010 & 2011 & 2012 & 2013 & 2014 & 2015 & 2016 & TOTAL \\
\hline Jan & 0 & 172 & 5 & 0 & 11 & 96 & 0 & 38 & 9 & 0 & 25 & 356 \\
Feb & 0 & 133 & 104 & 0 & 3 & 112 & 0 & 37 & 22 & 0 & - & 411 \\
Mar & 0 & 125 & 145 & 0 & 74 & 107 & 101 & 0 & 87 & 0 & - & 639 \\
Apr & 0 & 128 & 3 & 0 & 38 & 140 & 29 & 0 & 0 & 13 & - & 351 \\
May & 0 & 79 & 47 & 0 & 6 & 85 & 0 & 82 & 0 & 70 & - & 369 \\
Jun & 0 & 78 & 106 & 0 & 50 & 41 & 23 & 35 & 85 & 48 & - & 466 \\
Jul & 0 & 126 & 76 & 0 & 89 & 92 & 25 & 124 & 100 & 75 & - & 707 \\
Aug & 0 & 107 & 0 & 0 & 68 & 69 & 40 & 50 & 77 & 52 & - & 463 \\
Sep & 0 & 103 & 0 & 0 & 51 & 79 & 0 & 0 & 39 & 77 & - & 349 \\
Oct & 0 & 92 & 0 & 42 & 68 & 42 & 73 & 94 & 0 & 45 & - & 456 \\
Nov & 0 & 77 & 0 & 34 & 52 & 40 & 47 & 45 & 0 & 31 & - & 326 \\
Dec & 135 & 2 & 0 & 40 & 107 & 24 & 19 & 47 & 0 & 20 & - & 394 \\
Total & 135 & 1222 & 486 & 116 & 617 & 927 & 357 & 552 & 419 & 431 & 25 & $\mathbf{5 2 8 7}$ \\
\hline
\end{tabular}

data as it is clearly shown in Table 1 and Table 2 . As the number of observed days with data increases, there is also an increase days with instantaneous data though it's not 1:1 ratio. During the hot dry season, most of the atmosphere is sky clear which leads to higher recorded of data as compared to the rainy season with overcast atmosphere. It was observed from Table 2 that total amount of the 
instantaneous data was 5287.

\section{Result and Discussion}

\subsection{Temporal Variability of Aerosol Properties}

The daily variation of AOD440 nm was performed using a time series analysis. The annual mean of AOD for the ten years from 2007 to 2016 was about 0.25 , $0.28,0.18,0.27,0.27,0.29,0.29,0.32,0.26$ and 0.56 respectively. It can be seen in Figure 3 that the mean value of AOD for the year 2014 was higher compared to other years because most of the observations were made during the dry season of July to August which is considered as the high aerosol loading period while 2009 was recorded the lowest AOD values of about 0.18 since observations were made for shorter period. The high variability in AOD440 nm indicates a variety of aerosol types over this study area due to the transported air mass of different origins and characteristics.

Figure 4 shows a plot of the monthly statistics of aerosol optical properties and total precipitable water content which are presented as box-and-whiskers diagrams. The variability of the median values in each month is labeled with a circle. It can be clearly shown that AOD showed a distinct seasonal variation for this rural area with high values that mainly occurred in June-July-August (dry season) while the lowest amount was occurred during March-April-May (wet season). The seasonal means of AOD $440 \mathrm{~nm}$ were approximately $0.25 \pm 0.09$ in DJF, $0.21 \pm 0.06$ in MAM, $0.38 \pm 0.13$ in JJA and $0.23 \pm 0.08$ in SON. The highest monthly mean values of AOD was in July $(0.41 \pm 0.07)$ while the lowest was in November $0.16 \pm 0.03$ and May $0.19 \pm 0.07$ Figure 4(a). The appearance of high values of AOD $440 \mathrm{~nm}$ in dry season was related with the contribution of mixed and marine aerosols as shown in Figure $7(\mathrm{~b})$ though the previous literatures

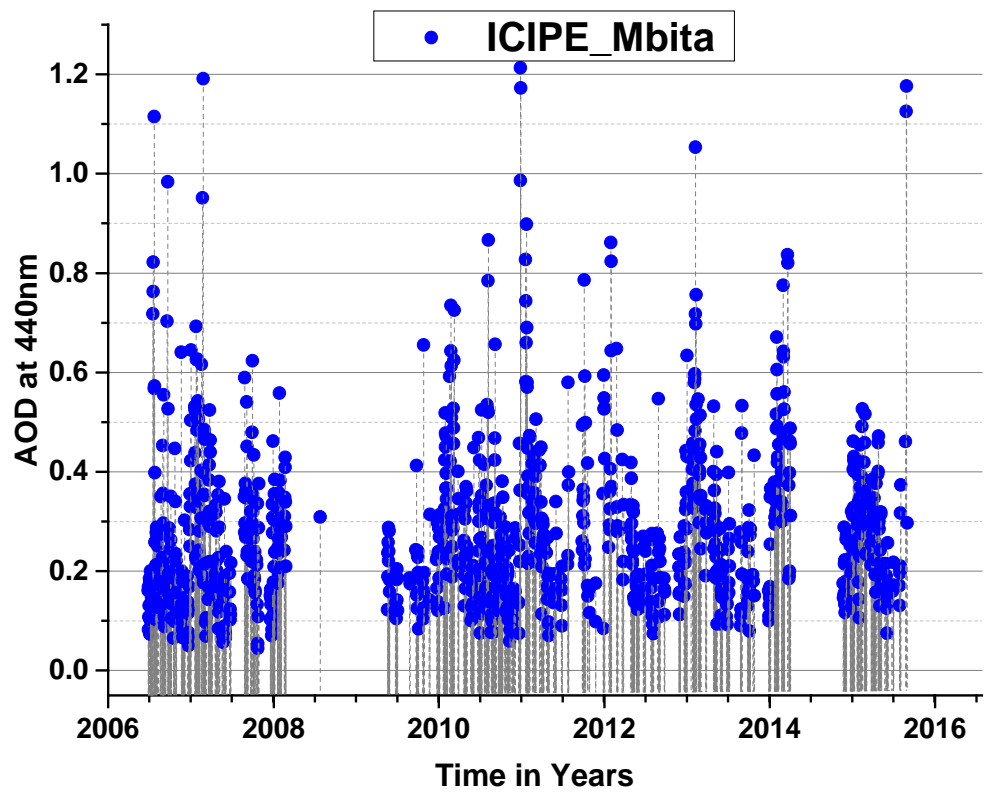

Figure 3. Monthly means AOD for ICIPE Mbita from 2007 to 2015. 

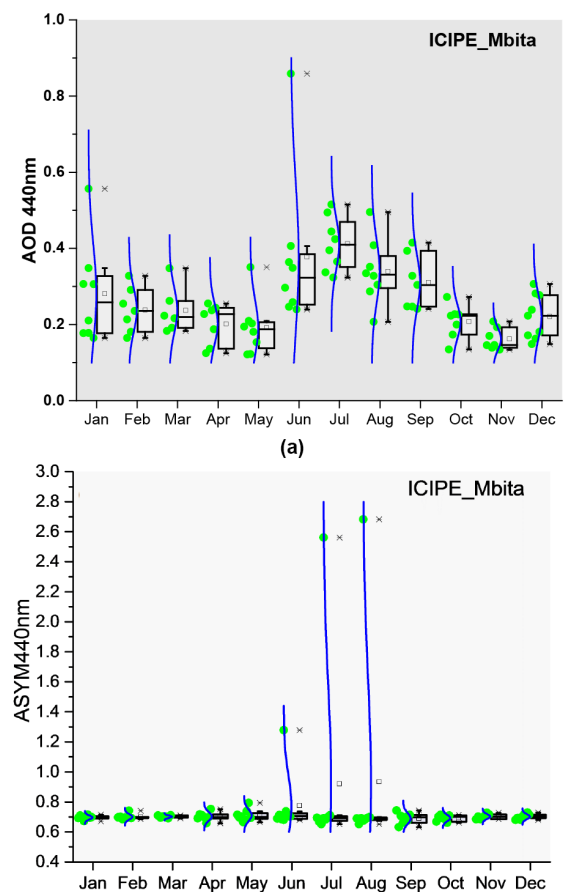

(d)

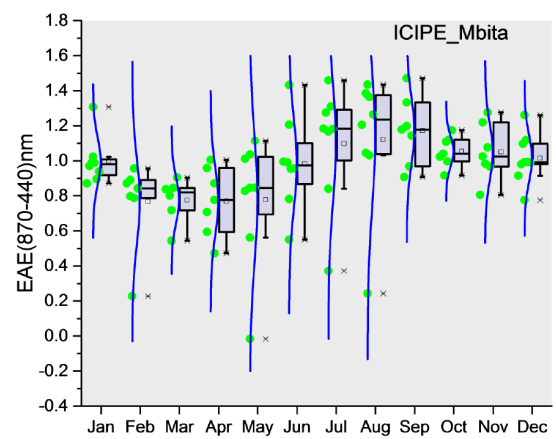

(b)

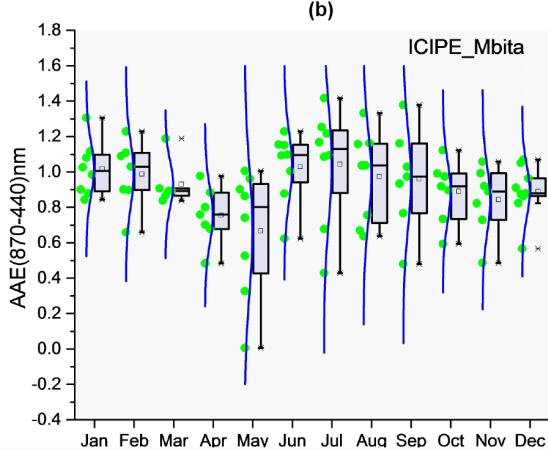

(e)

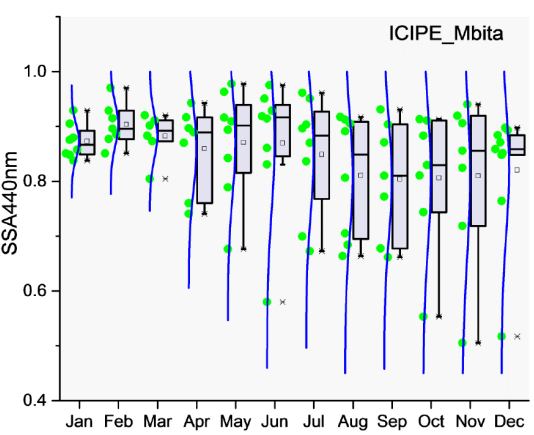

(c)

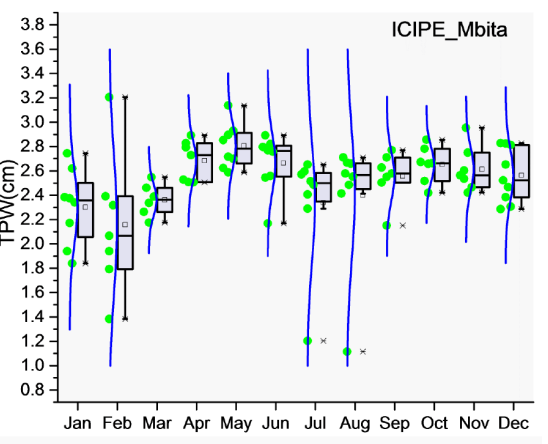

(f)

Figure 4. Box plots of monthly variation of Aerosol Optical Depth at $440 \mathrm{~nm}$ (AOD $440 \mathrm{~nm}$ ); Extinction Ångström Exponent (EAE); Single Scattering Albedo at $440 \mathrm{~nm}$ (SSA440 nm); Asymmetric parameter (ASYM); Absorption Ångström Exponent (AAE) and Total amount of Precipitable Water (TPW) for ICIPE Mbita from year 2007 to 2016. In each box, the central bar is the median and the lower and upper limits are the first and the third quartiles, respectively. The lines extending vertically from the box indicate the spread of the distribution with the length being 1.5 times the difference between the first and the third quartiles. The cycle symbols indicate geometric means. The $\mathrm{x}$-axis shows time in months from January to December.

work indicates that the dominant aerosols originates from dust and biomass burning particles emitted from surrounding rural areas [11].

The monthly mean values of AOD was highest in July $(0.41 \pm 0.07)$ and lowest in November $0.16 \pm 0.03$ and May $0.19 \pm 0.07$. It can be seen that AOD, AEA and AAE graphs have similar patterns of variation such that when there is a rising of AOD parameter the other parameters also increase Figure 4(a), Figure 4(b) and Figure 4(e) whereas the relationship between AOD and TPW has negative correlation between them.

It was observed that low EAE values occurred during the wet season while high values were recorded during the dry season Figure 4(b). This may be related to high amount of TPW during wet season and low during dry season Figure 4(f). The annual mean values of SSA is $0.85 \pm 0.10$ while the relatively high monthly values of SSA occurred in the months of June to July (Dry season) Figure 4(c). This is due to the dominance of fine mode aerosols and low amount of water vapor in the atmosphere during this dry period. Ångström exponent $(\alpha)$ was a measure of the wavelength dependence of AOD and a good indicator of aerosol particle-size. It is clearly depicted from Figure 4(e) that the values of AAE are high in the dry months and low in the wet months. These results signify the presence of greater contribution of aerosols in the fine-mode to the extinction for the present study period [12]. Lastly the variations in ASYM Figure 4(d) 
are not apparent; the values only vary from 0.70 to 0.93 .

\subsection{Seasonal Frequency Distribution of AOD}

Figure 5 shows the frequency percentage occurrence which is categorized by individual season for the AOD at $440 \mathrm{~nm}$. Due to the different emission sources and atmospheric conditions, Figure 5 indicates that there is a large difference in the AOD distribution for each season although all the seasons indicate a unimodal distribution which can be seen from log normal blues curve. During the DJF period, the modal value was 0.18 of $60 \%$ frequency of occurrence while for the MAM season the modal values was 0.20 of $50 \%$ frequency of occurrence meanwhile during the dry season of JJA, the modal values was 0.35 with $40 \%$ frequency of occurrence and lastly for SON season, the modal value was at 0.25 with $40 \%$ also for frequency of occurrence.

It was also observed that there was inverse proportionality between the wavelength and the AOD, as the wavelength increased there was a decreasing in the values of AOD. During the dry season the values of AOD were higher than other seasons, the same trend was observed for the AE with higher values during JJA and lower in the wet season which was similar with what was observed by [13].

\subsection{Aerosols Volume Size Distribution}

Due to the breakup of large particles which have originated from multiple sources of particles, it is evident that these particles have grown growth mechanisms in the system which leads to bimodal graphs. From Figure 6, it is evident that the seasonal variation of aerosols volume size distribution at $440 \mathrm{~nm}$ in the rural area of Mbita are mainly of natural origin but with a moderate of influence of anthropogenic sources. The number of distribution is characterized by two modes at a radius of 0.25 to $0.3 \mu \mathrm{m}$ for fine mode while the mass distribution for coarse mode is centered on 7 to $7.5 \mu \mathrm{m}$ for all the four seasons. Figure 6(a) which is a transitional period between long rain season and short rain periods clearly shows dominance coarse particle in size range $>0.02 \mu \mathrm{m}$ centered a radius of $8 \mu \mathrm{m}$. During the long rain period Figure 6(b), the graph almost flattened at the radius of $0.2 \mu \mathrm{m}$ remaining with only one peak centered at $8 \mu \mathrm{m}$. This may have resulted from growth mechanism of the fine particles from rain water droplets leading to coarse mode particles.

During the hot dry season Figure 6(c), both fine mode and coarse mode particles are clearly shown. The amount of water vapor in the atmosphere during this period is less. This may have contributed to the occurrence of both aerosols particles, though it can be seen that fine particles were more dominant with the highest peak of VSD at a value of $0.03 \mu \mathrm{m}^{3} / \mu \mathrm{m}^{2}$ than all other seasons. Figure $6(d)$, during the short rain season, the concentration of fine particles diminishes as it can be seen from the graph due to the interaction with rain water. The high values of VSD in the fine mode which is observed during the dry season is due to the contribution of more biomass burning during the land preparations and 

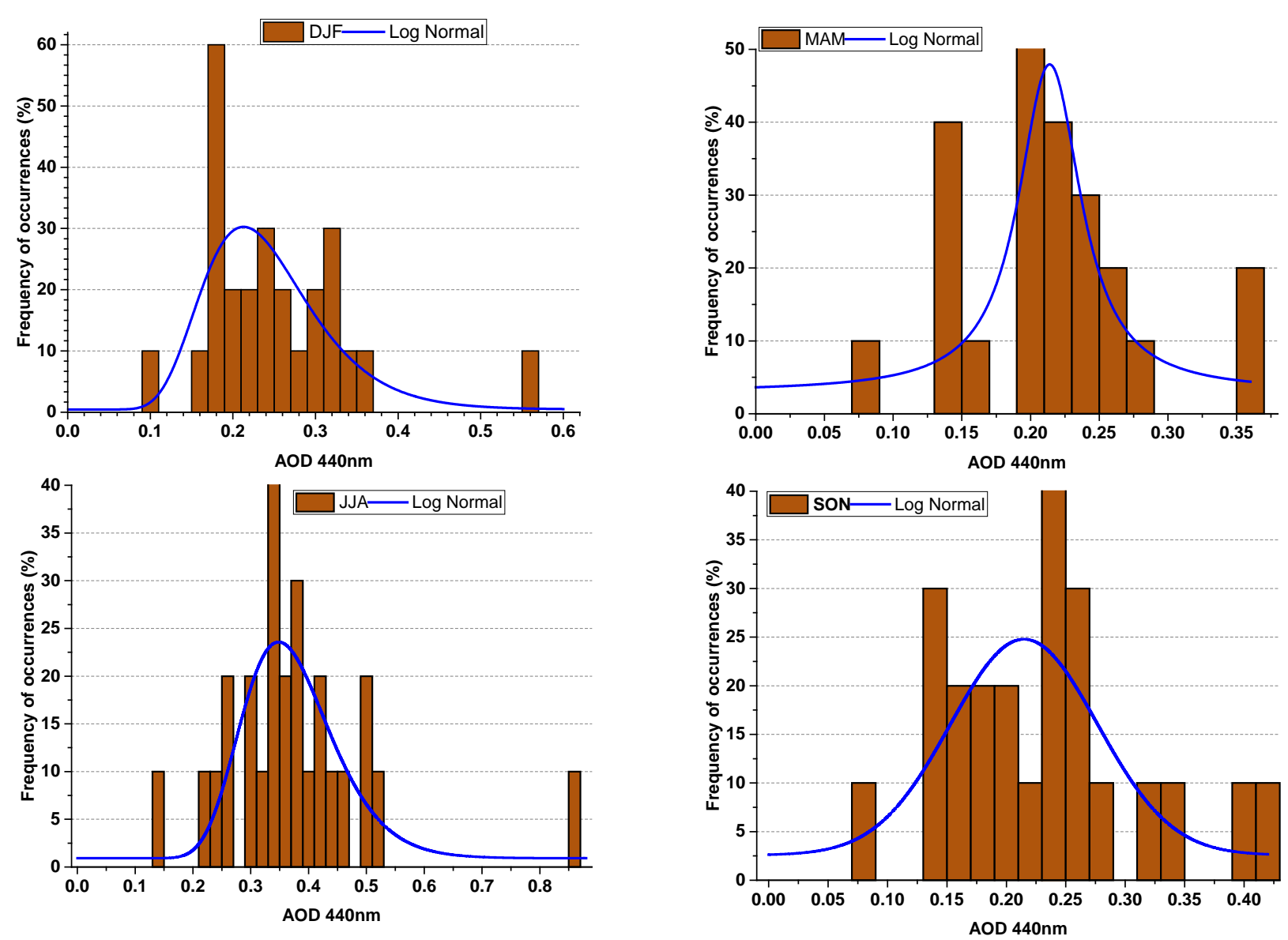

Figure 5. Seasonal frequency distribution (\%) of AOD at $440 \mathrm{~nm}$ over ICIPE_Mbita for DJF, MAM, JJA and SON seasons. Blue line represent the Log Normal computational for the data.

cultivations for the crops and long range transport of dust and urban-industrial wastes [9].

\subsection{Major Aerosol Types}

Different aerosols in the atmosphere can be classified into different types by using scatter plot techniques centered on their abundance such as AOD against $\alpha$. AOD vs $\alpha$ which are both the functions of wavelength was preferred for this work because there was large instantaneous availability of data as compared to other cases like FMF, AAE and SSA which have averaged daily data as it was suggested by [14]. Five different classes of aerosols were identified by these techniques namely; Marine, Desert dust, Biomass burning/Urban Industrial and Clean Continental as seen in Figure 7. Different threshold values were used to classify the aerosol, for example marine influence aerosols ranges between $0<\mathrm{AOD}>0.3,0<a>0.85$ which corresponds to $26.1 \%$ of total contribution Figure 7(b). Aerosols originates from desert dust and BB/UI ranges between $0.6<\mathrm{AOD}>1.8,0<\alpha>0.6$ and $0.6<\mathrm{AOD}>1.8,1<\alpha>1.75$ respectively with a small percentage of 1.6 while clean continental threshold values ranges between $0.6<\mathrm{AOD}>0.3,1<\alpha>1.8$ (26.1\%). Lastly a large portion corresponding to $44.2 \%$ 


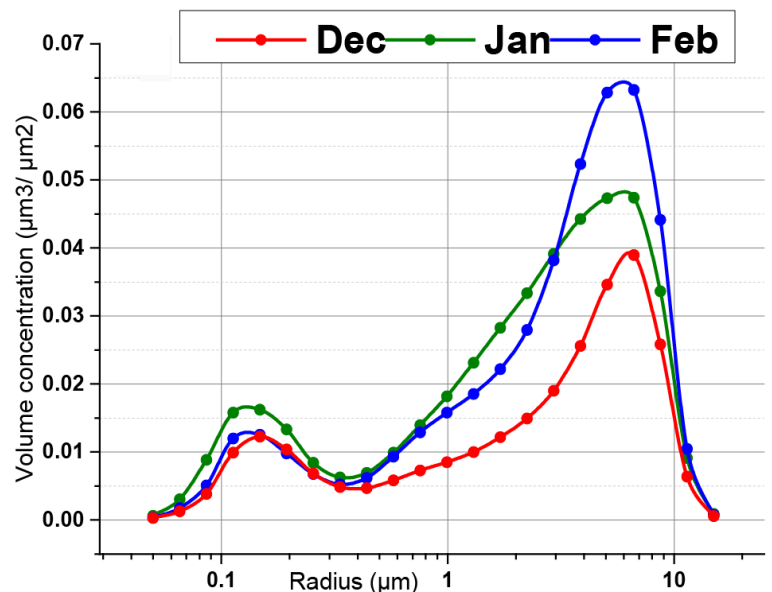

(a)

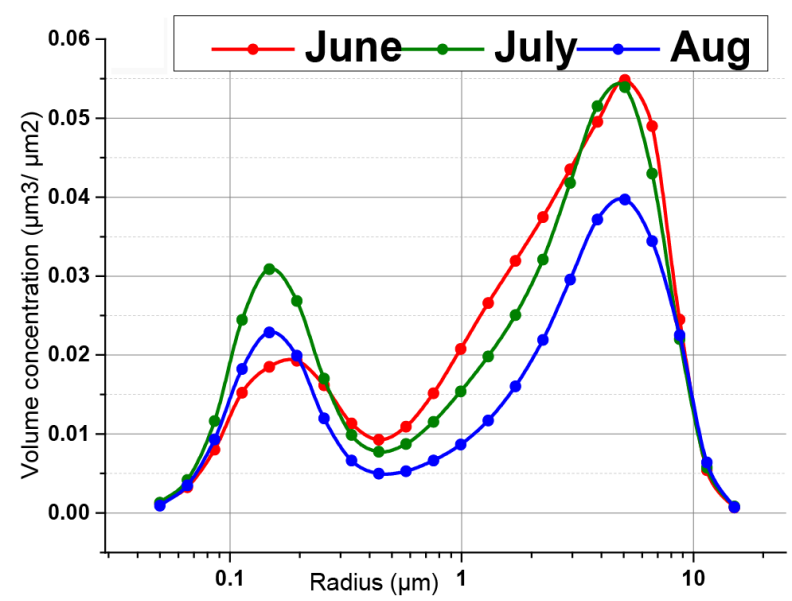

(c)

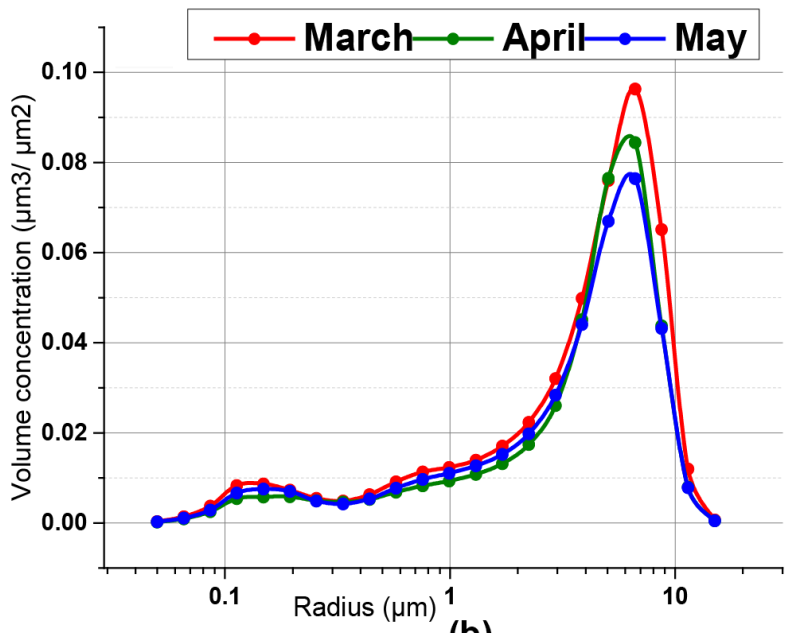

(b)

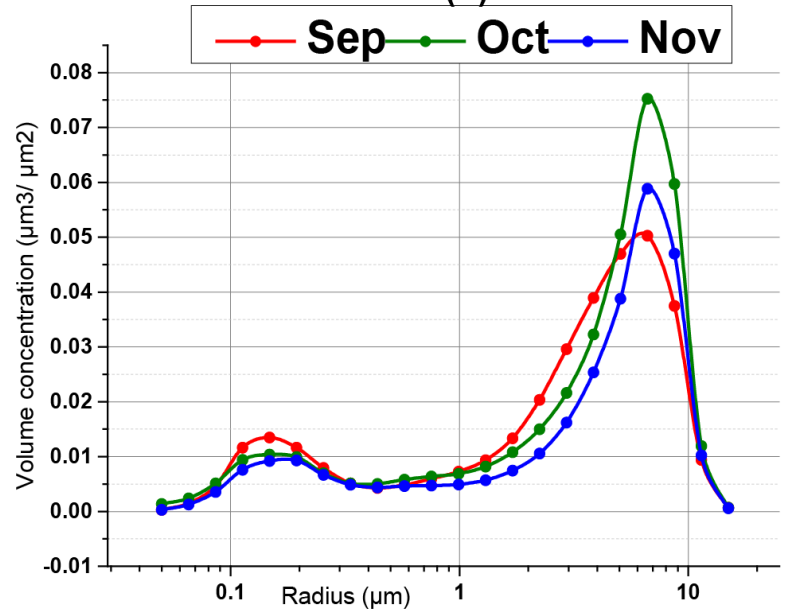

(d)

Figure 6. Atmospheric aerosols volume size distribution in $\left(\mu \mathrm{m}^{3} / \mu \mathrm{m}^{2}\right)$ verses particle sizes in ( $\left.\mu \mathrm{m}\right)$ graphs for DJF, MAM, JJA and SON seasons. The radius ranges from $0.05 \mu \mathrm{m}$ to $15 \mu \mathrm{m}$.

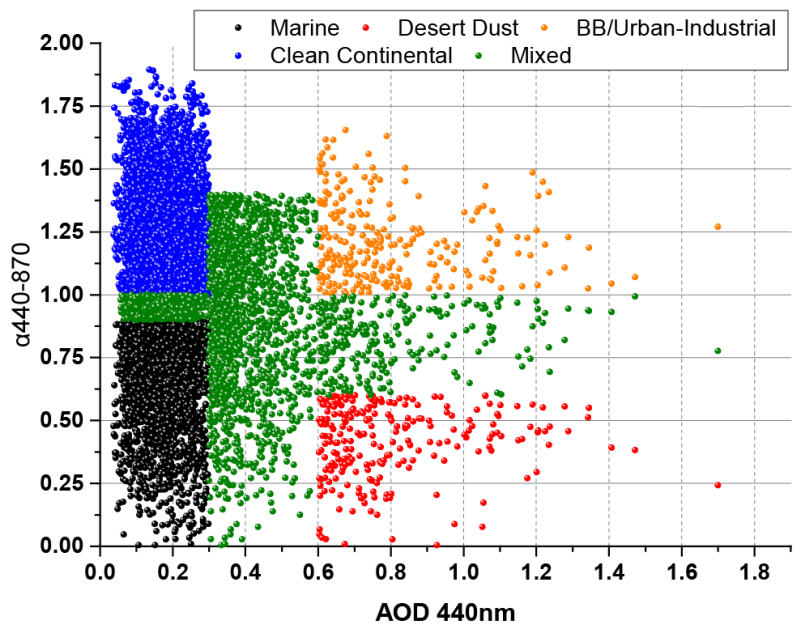

(a)

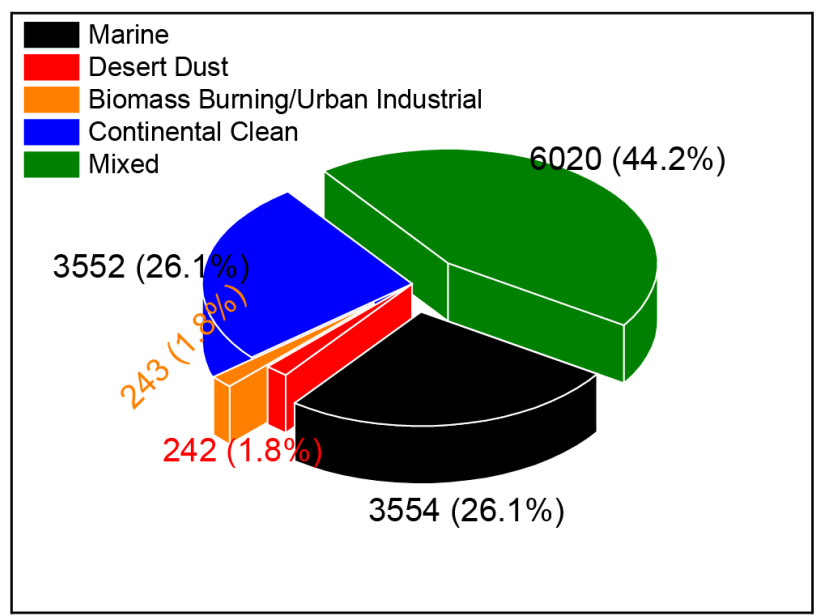

(b)

Figure 7. Scatter plot of AOD440 nm versus a (440 - 870) for identification of the dominant aerosol types (a) over ICIPE Mbita in the period December 2006 to January 2016, colors indicate the aerosol types. (b) There percentage of each aerosol type during the study period. BB stands for Biomass Burning. 
of scattered points were grouped as mixed aerosols. It can be seen that aerosols originated from marine environment corresponding to (26.1\%) of 3,554 because ICIPE Mbita station is situated next to Lake Victoria.

\subsection{Classification of Aerosol Type}

Figure 8 demonstrates the seasonal variations of aerosol classification at four different local seasonal periods over ICIPE Mbita namely; DJF, MAM, JJA and SON. From Figure 8(b), it can be seen that very few data points at low AOD 550 $\mathrm{nm}$ values during MAM season were outside the classification scheme which may be caused due to small uncertainties errors in $\mathrm{dAE}$ vs $\mathrm{AE}$ estimation while evaluating AOD 675 whereas other plots all over the data are within the classification scheme.

In JJA season Figure 8(c), AOD $>1.2 \mathrm{~nm}$ of $\left(\mathrm{R}_{\mathrm{f}} \sim 0.1-0.15 \mu \mathrm{m}\right)$ is of $\eta 90 \%$ however most aerosols clustering falls on the positive $\mathrm{dAE}$ with large clustering of fine mode AOD $>1 \mathrm{~nm}$ concentration found within the range of $R_{f}(0.2-0.3)$ $\mu \mathrm{m}$ with $\eta(30-50) \%$. The same scenario with large clustering of fine mode AOD $>1 \mathrm{~nm}$ concentration is found within the range of $R_{f}(0.2-0.3) \mu \mathrm{m}$ with $\eta$ $30 \%$ occurring during MAM season Figure $8(\mathrm{~b})$ however coarse mode occur more frequently in this season than in other seasons with $(0.4<\mathrm{AOD}>1.2) \mathrm{nm}$ of $\eta(30-50) \%$ and $\mathrm{R}_{\mathrm{f}}(\sim 0.05-0.10) \mu \mathrm{m}$ were on the positive dAE. Both DJF and SON season show similar results although during SON there is large clustering of $(0<\mathrm{AOD}>0.6) \mathrm{nm}$ and $\mathrm{R}_{\mathrm{f}}(\sim 0.1-0.15) \mu \mathrm{m}$ which are concentrated in $\mathrm{dAE}(0$ $0.2)$ positive side with $\eta(50-70) \%$ within the range of $A E(0.8-1.6) n m$, Figure $8(d)$.

The positive $\mathrm{dAE}$ values indicates that these aerosols are of bimodal distribution having a large coarse-mode fraction between $\eta(50-70) \%$, whereas, the $\mathrm{dAE}$ values near to zero Figure 8(a) represents the lesser dominance of coarse-mode particles relative to fine-mode with $\eta$ values of $70 \%$.

This work emphasizes on obtaining the area of interest-scale characterization of the aerosol properties. It can be seen that small differences in the dAE vs $\alpha$ plots revealed establishing homogeneity in aerosol load although there was also present of small percentage of heterogeneity in aerosol load. The more positive $\mathrm{dAE}$ with increasing $\mathrm{AOD}$ is an indication of coarse-mode dominance under high AODs. As seen in Figure 8, even though several conclusions regarding these aerosol characteristics over ICIPE Mbita are apparent, the small scatter in the data leads to small visual uncertainties.

\subsection{Hysplit-4 Trace the Source of Dust Aerosols}

In order to understand and monitor the major sources of pollutants arriving at ICIPE Mbita, The Hybrid Single Particle Lagrangian Integrated Trajectory Model (HYSPLIT) [6] [7] of NOAA for backward trajectories analysis. The data was chosen based from Table 1 and Table 2 for the month of July in 2015. This month recorded the longest time duration data for 23 days with its corresponding 


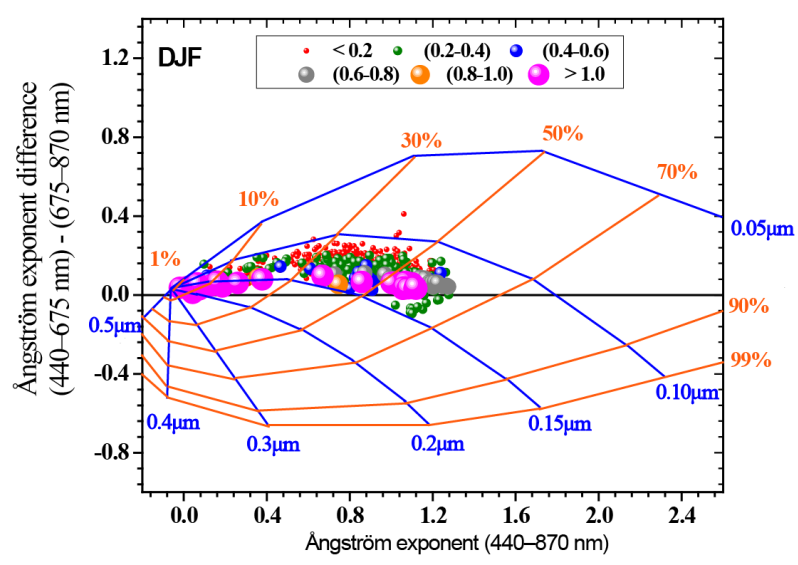

(a)

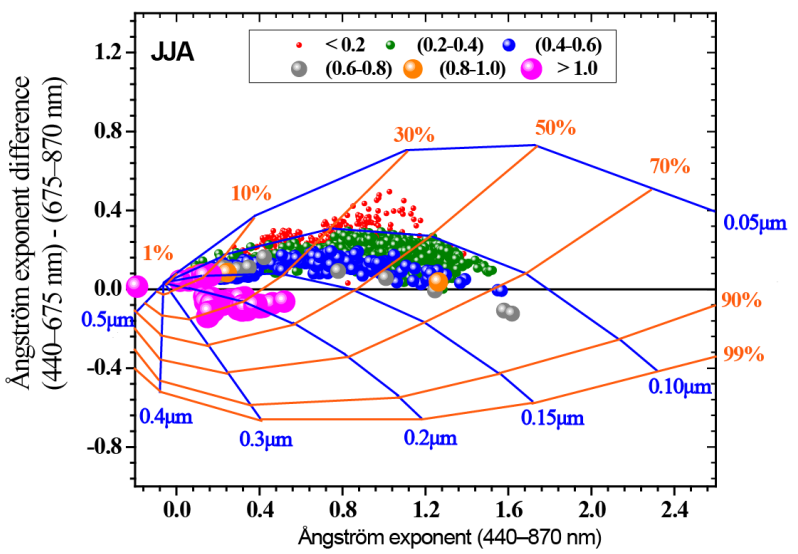

(c)

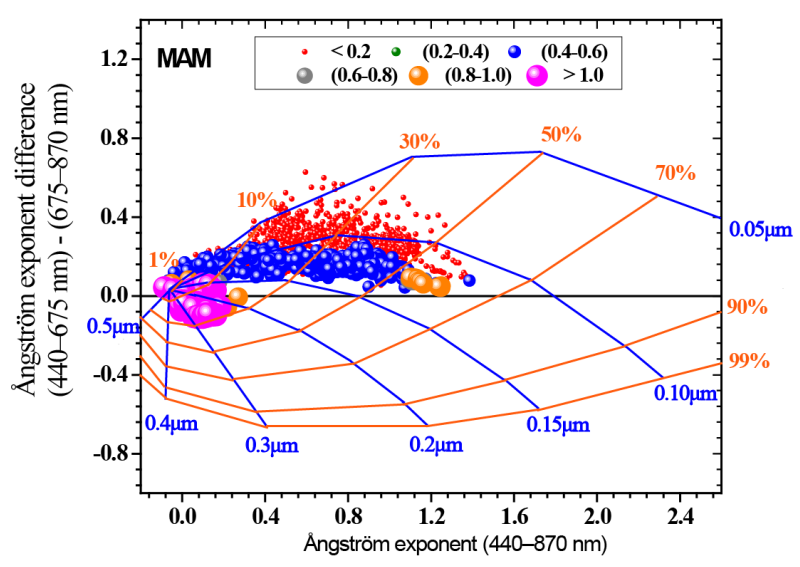

(b)

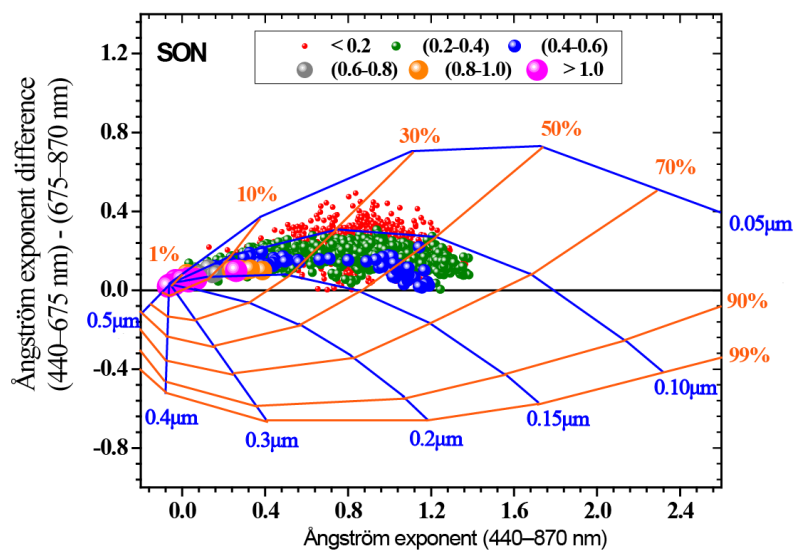

(d)

Figure 8. Ångström exponent difference, $\mathrm{dAE}=\mathrm{AE}(440-675 \mathrm{~nm})-\mathrm{AE}(675-870 \mathrm{~nm})$, as a function of $\mathrm{AE}(440-870 \mathrm{~nm})$ and AOD $500 \mathrm{~nm}$ over ICIPE Mbita station for the four local seasons; (a) DJF, (b) MAM, (c) JJA and (d) SON. The blue lines designate the fixed effective radius (Rf) of the fine-mode while the orange lines designate a fixed fraction ( $\eta$ ) of fine-mode to the AOD at $675 \mathrm{~nm}$. The increasing size of the circle symbols indicates an increasing of AOD.

number of instantaneous data of 75. A 120 hours (5 days) back trajectories at different altitudes of 1,130, 2,000 and 3,000 meters above mean sea level was used since this station is at an altitude of $1,125 \mathrm{~m}$. Generally, observations show Figure 9 shows most of the trajectories were originated from the southern hemisphere from south east direction. Figure 9(a), the trajectories at the altitude of 1,130 m amsl (red cycles) starts from the coastline of Mozambique in Indian Ocean and propagates along the coastline of Tanzania as it enters into Kenya, located at the border of Tanzania and the coast side of Kenya [15] [16]. This trajectory passes through industrial, agricultural and urban areas of Kenya toward western region of Kenya which might have carried large amounts of fine mode particles and industrial pollutants. For the trajectories, the altitudes of 2,000 and 3,000 originate from the central Ethiopian highland and Saudi Arabian respectively.

These trajectories propagate through the arid and semi-arid regions of Kenya, which brings in dust aerosols with them. Figures 9(a)-(d) shows air masses except level of $3,000 \mathrm{~m}$ from the $2^{\text {nd }}$ week until the $5^{\text {th }}$ week and for the 

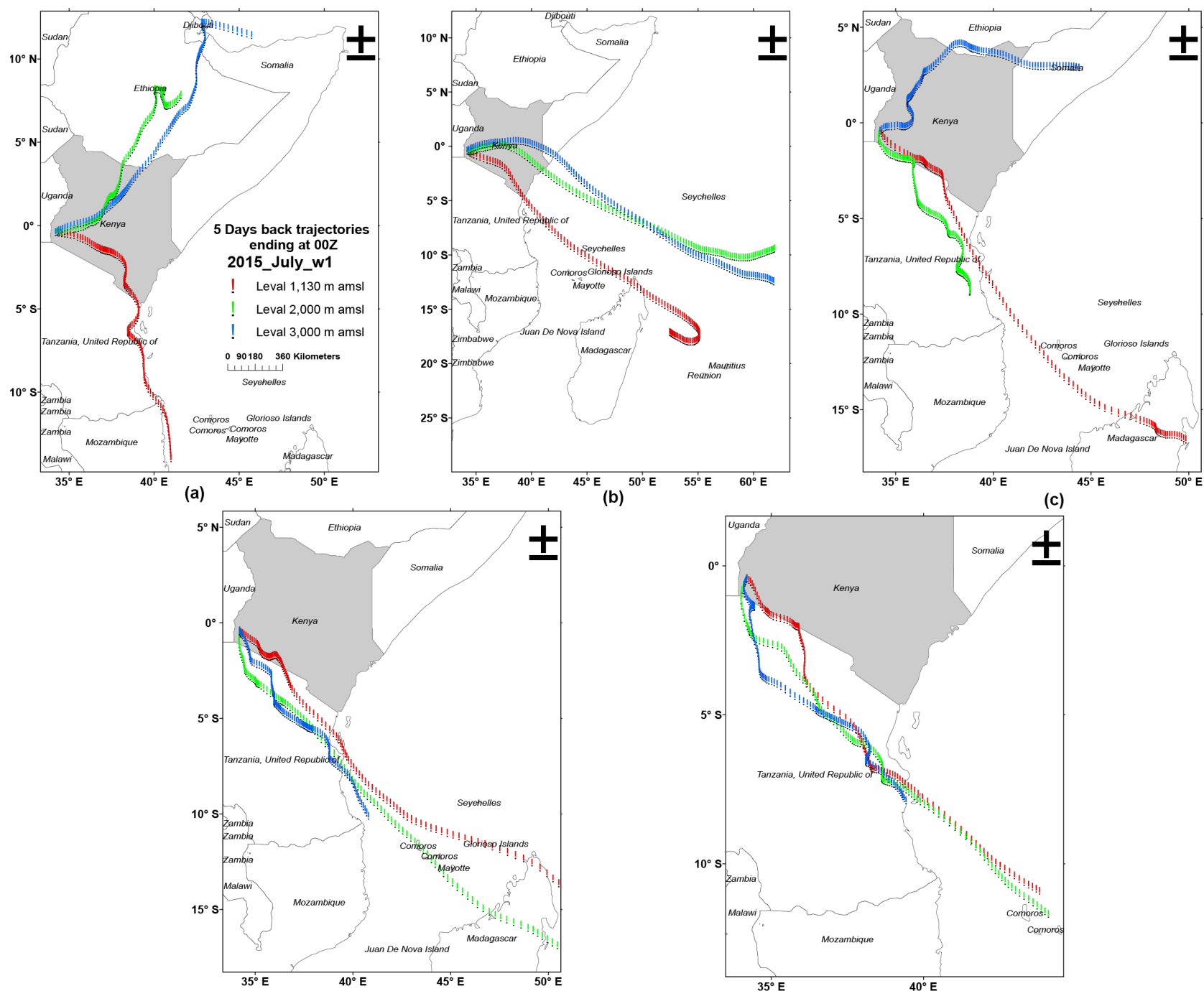

(d)

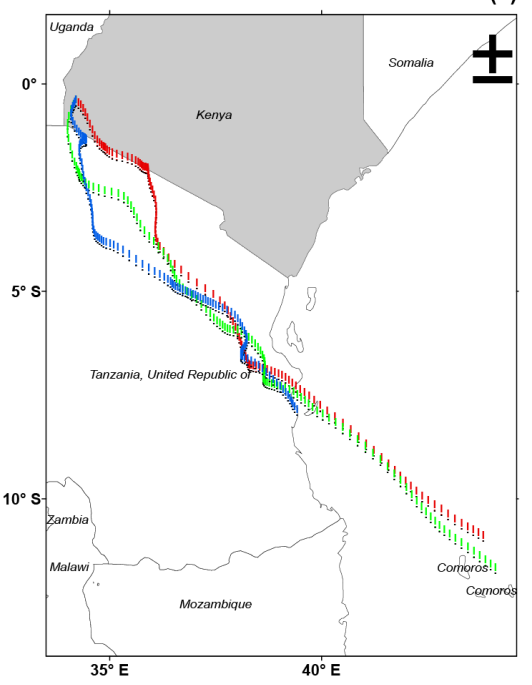

(e)

Figure 9. 120 hours HYSPLIT backward trajectories ending at 00Z over ICIPE_Mbita at different altitude of 1130 (red cycles), 2,000 (green cycles) and 3000 (blue cycles) meters amsl for week 1 to week 5 (a) to (e) 2015 July, while (f) is wind flow patter on week 4.

Figure $9(c)$ it indicates that the air masses had a strong maritime influence originating from the Indian Ocean and Madagascar Island, which are one of the major sources of causing sea salts aerosols and fine mode smoke plumes in East Africa [4].

During summer in the northern hemisphere, the strong south easterly surface winds flow is predominantly as it can be seen from Figure 10. Through the application of a simple technique of wind analysis it can be seen that a persistent high-speed of winds of about (15 - 30) Knots in the form of low level jet streams, exists in the lower layers which originates from the tip of Madagascar which is then blown to Kenyan coastline as southerly. These southerly winds carry sea salts and dust from Indian Ocean and Madagascar Island respectively. Due to topographical intensification of the flow, the speed is generally reduced as winds 

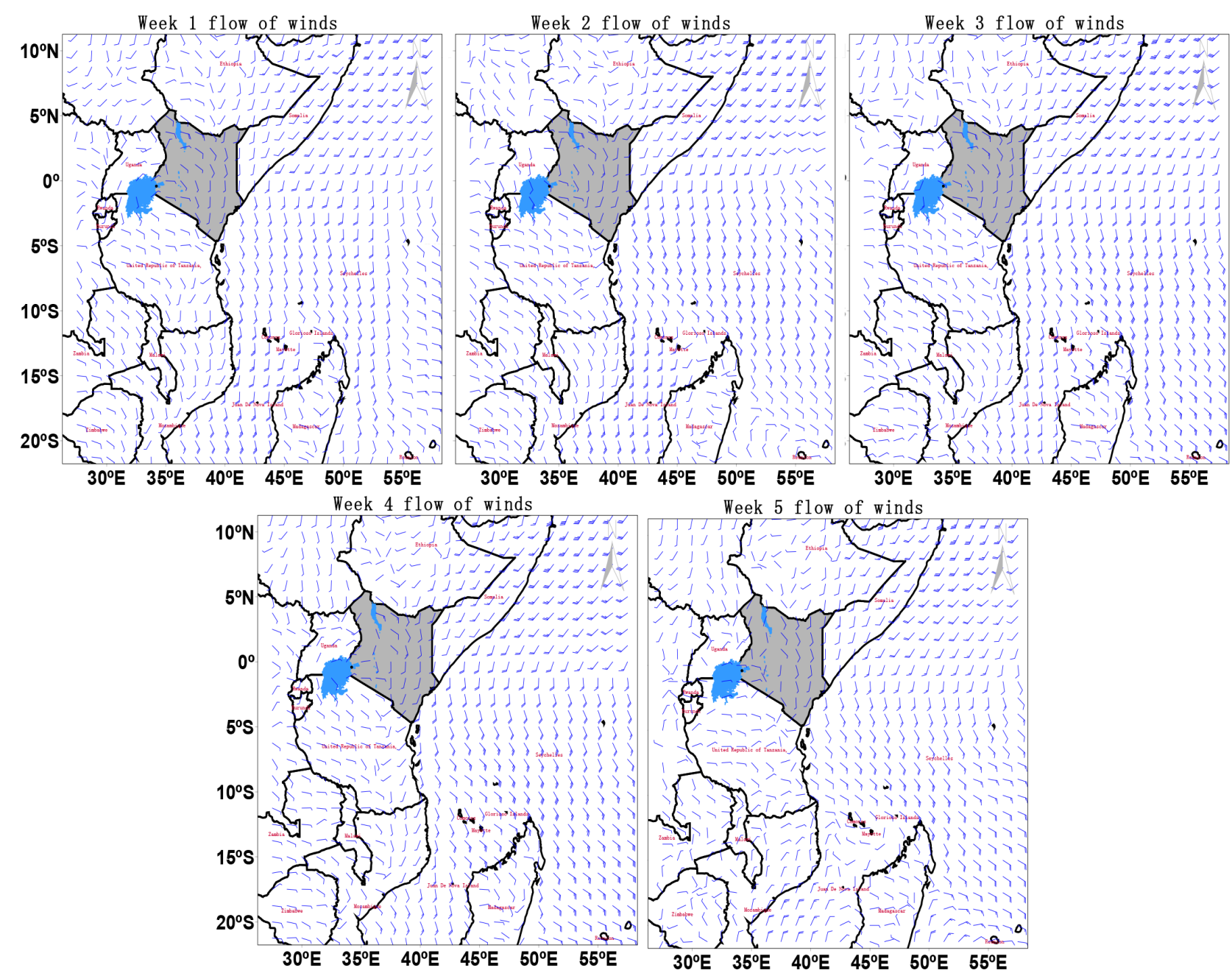

Figure 10. General flow of winds in knots plotted with wind bars during July.

converges into western parts of Kenya leading to more concentration of sea salts and dust particles to the study area.

\section{Summary and Conclusion}

This study focused on the aerosols classification and aerosol identification source regions through backward trajectory analysis using Sunphotometer ground based and HYSLPIT data. The Aerosol optical and micro-physical distinctive, size distributions and trajectories analysis of the aerosols measured on-board have been summarized. These results have been discussed in detail. Table 1 and Table 2 show the results for both number of days and number of instantaneous data for the ICIPE Mbita AERONET site in Kenya whereby it was observed that there was missing data for few months due to the malfunction of the measuring instruments. Aerosols of optical and micro-physical characterization which are of great importance especially for the identification of dominance aerosols were studied and its physical properties were determined, indicating 
differences in composition.

From the analysis of the seasonal frequency distribution, all the four seasons indicated a unimodal distribution of AOD while the seasonal variation of AOD shows an inverse proportionality between the wavelength and the AOD values. This technique was useful for this research. An additional multipurpose tool of $\mathrm{dAE}$ vs AE classification scheme was utilized for this research work. This scheme aided in exploring the information on aerosol-particle size for different aerosol types. This revealed that mixed and marine aerosols were dominant in this area whereas biomass burning/urban-industrial and dust aerosols were of minimal influence (Figure 7(b)).

The monthly variation of AOD $440 \mathrm{~nm}$ presents significant seasonal variations with two peaks appearing in JJA and DJF seasons. The High AOD during hot dry periods was associated with high marine aerosols and higher temperatures leading to high evapotranspiration rates from the nearby Lake Victoria Figure 2 and mixed local aerosols. Secondly the local mixed emissions were associated with the dominance of fine mode particles while in rainy season coarse particles were predominant. Through the application of HYSPLIT model and simple winds analysis techniques, Figure 9 and Figure 10 show that the measuring site is affected by aerosols from difference sources both from nearby surrounding while others come from miles far away.

\section{Acknowledgements}

First and foremost Misiani, NIU and Lü wish to extend our sincere gratitude to the Principal Investigators and their staff in establishing and maintaining the AERONET site and for providing online data. Secondly, we also owe our sincere thanks to the NOAA Air Resources Laboratory for computing back trajectories using the HYSPLIT model. Lastly Misiani is also thankful to the People's Republic of China Government and Kenya Meteorological Department for granting him a fellowship and study leave, respectively, without which this work will not have been possible. This study was completed as part of MSc. Thesis at the Nanjing University of Science and Technology, with the support of the Ministry of Commerce of the People's Republic of China scholarship 2016.

\section{References}

[1] Levy, R.C., et al. (2007) Second-Generation Operational Algorithm: Retrieval of Aerosol Properties over Land from Inversion of Moderate Resolution Imaging Spectroradiometer Spectral Reflectance. Journal of Geophysical Research Atmospheres, 112, 1-21. https://doi.org/10.1029/2006JD007811

[2] Nabat, P., et al. (2014) Direct and Semi-Direct Aerosol Radiative Effect on the Mediterranean Climate Variability Using a Coupled Regional Climate System Model. Climate Dynamics, 44, 1127-1155.

[3] Holben, B.N., et al. (1998) Aeronet-A Federated Instrument Network and Data Archive for Aerosol Characterization. Remote Sensing of Environment, 66, 1-16. https://doi.org/10.1016/S0034-4257(98)00031-5 
[4] Benas, N., et al. (2013) Aerosol Shortwave Direct Radiative Effect and Forcing Based on MODIS Level 2 Data in the Eastern Mediterranean (Crete). In: Helmis, C.G. and Nastos, P.T., Eds., Advances in Meteorology, Climatology and Atmospheric Physics, Springer Berlin Heidelberg, Berlin, Heidelberg, 917-922. https://doi.org/10.1007/978-3-642-29172-2_128

[5] Gobbi, G.P., Kaufman, Y.J., Koren, I. and Eck, T.F. (2007) Classification of Aerosol Properties Derived from AERONET Direct Sun Data. Atmospheric Chemistry and Physics, 7, 453-458. https://doi.org/10.5194/acp-7-453-2007

[6] Draxler, R.R. and Hess, G.D. (1998) An Overview of the HYSPLIT_4 Modelling System for Trajectories. Australian Meteorological Magazine, 47, 295-308.

[7] Draxler, R. (1998) An Overview of the HYSPLIT Modeling System for Trajectory and Dispersion Applications.

[8] Kenya National Bureau of Statistics (KNBS); ORC Macro. (2010) Kenya Demographic and Health Survey 2008-2009. Health, San Francisco, 1-314.

[9] Makokha, J.W. and Muthama, J.N. (2017) Aerosol Optical Depth and Precipitation Rate Projections over East Africa Utilizing Self Organizing Map. The International Journal of Science \& Technoledge, 5, 166-175.

[10] Xu, X.G., et al. (2015) Retrieval of Aerosol Microphysical Properties from AERONET Photopolarimetric Measurements: 2. A New Research Algorithm and Case Demonstration: A New Inversion Algorithm for Aeronet. Journal of Geophysical Research: Atmospheres, 120, 7079-7098.

https://doi.org/10.1002/2015JD023113

[11] Makokha, J.W. (2013) Investigation of Radiative Characteristics of the Kenyan Atmosphere due to Aerosols Using Sun Spectrophotometry Measurements and the COART Model. Aerosol and Air Quality Research. https://doi.org/10.4209/aaqr.2012.06.0146

[12] Lyamani, H., Olmo, F.J., Alcántara, A. and Alados-Arboledas, L. (2006) Atmospheric Aerosols during the 2003 Heat Wave in Southeastern Spain I: Spectral Optical Depth. Atmospheric Environment, 40, 6453-6464. https://doi.org/10.1016/j.atmosenv.2006.04.048

[13] Lv, R., Yu, X.N., Jia, H.L. and Xiao, S.H. (2017) Aerosol Optical Properties and Direct Radiative Forcing at Taihu. Applied Optics, 56, 7002. https://doi.org/10.1364/AO.56.007002

[14] Pace, G., et al. (2006) Aerosol Optical Properties at Lampedusa (Central Mediterranean)-1. Influence of Transport and Identification of Different Aerosol Types. Atmospheric Chemistry and Physics Discussions, 5, 4929-4969. https://doi.org/10.5194/acpd-5-4929-2005

[15] Zachary, M., Yin, L. and Zacharia, M. (2018) Aerosol Optical Depth Pathways and Sources; Lake Victoria Basin. OALib, 5, 1-11. https://doi.org/10.4236/oalib.1104393

[16] Zachary, M., Yin, L. and Zacharia, M. (2018) Application of PSCF and CWT to Identify Potential Sources of Aerosol Optical Depth in ICIPE Mbita. Open Access Library Journal, 5, 1-12. https://doi.org/10.4236/oalib.1104487 